\title{
Degradation Rates of Native versus Exotic Leaves in a Tributary of the Yellow River in Georgia
}

\author{
Bagie George, Christopher Brandon, Michael Erwin \\ School of Science \& Technology, Georgia Gwinnett College, Lawrenceville, USA \\ Email: bgeorge@ggc.edu
}

How to cite this paper: George, B., Brandon, C. and Erwin, M. (2017) Degradation Rates of Native versus Exotic Leaves in a Tributary of the Yellow River in Georgia. American Journal of Plant Sciences, 8, 19671976.

https://doi.org/10.4236/ajps.2017.88132

Received: June 14, 2017

Accepted: July 25, 2017

Published: July 28, 2017

Copyright $\odot 2017$ by authors and Scientific Research Publishing Inc. This work is licensed under the Creative Commons Attribution International License (CC BY 4.0).

http://creativecommons.org/licenses/by/4.0/

\begin{abstract}
Forested aquatic streams depend heavily on forest canopy input. This input is a primary resource for the macroinvertebrate fauna. As a result, changes in the canopy impact the aquatic ecosystem. The focus of this study was to identify leaf degradation rates to determine resource availability for invertebrate communities. Specifically, leaf degradation rates were determined for oak, poplar, maple and kudzu. Oak, poplar, and maple are established stream canopy vegetation while kudzu is an invasive species. By comparing leaf degradation rates of native vs. exotic leaves, it provides an insight to changes in community structure. Furthermore, these changes in the plant canopy biodiversity have long-term implications for stream health.
\end{abstract}

\section{Keywords}

Exotic Species, Kudzu, Stream Health

\section{Introduction}

Forested streams are inundated with the leaves from local vegetation, and surrounding canopy and these streams are impacted by the influx of this organic material. This vegetation for many aquatic organisms provides them with habitat as well as nutritional resources [1] [2]. As these leaves fall into the aquatic environment, they begin to degrade and release nutrients. Plant litter is the most important and dominant energy source in a stream's food web [3] [4]. It has been estimated that streams surrounded by deciduous forests receive up to $99 \%$ of energy input from the surrounding vegetation [4], and macroinvertebrates rely on this leaf-litter to meet nutritional needs [5] [6] [7] [8]. This relationship regulates the rate of leaf decomposition and the introduction of organic material into the stream ecosystem. Therefore, a stream's functionality is closely related 
to the processing of organic material [9] [10].

Several factors drive leaf degradation. For example, water temperature, chemical content, dissolved oxygen, aquatic macroinvertebrate abundance, water flow, and the vegetation biodiversity are several factors that affect leaf degradation [2] [6] [9]. Changes in the natural riparian vegetation such as of exotic or invasive species can further influence the stream ecosystem. The introduction of species such as kudzu causes the available vegetation to be less diverse and may further alter the macroinvertebrate abundance and breakdown rate. Kudzu quickly dominates an area and decimates the diversity of available flora [11] [12] [13]. Moreover, native species are physically dominated by kudzu [11] [12] [13]. As kudzu conquers its surrounding environment, there may be a decrease in nutritional options, which could result in less diversity of animal species [14]. Not only is the terrestrial environment impacted by the prevalence of kudzu, but there are ecological implications to the surrounding watersheds. Kudzu affects the water chemistry of stream ecosystems, and its presence can specifically lead to an overabundance of nutrients such as isoprene and nitrogen [11]. Contamination by these substances has damaging consequences to the water system, which include but are not limited to accumulation of harmful organic substances, excessive algae, and oxygen-depleting compounds [11] [15]. Water sources, which have been consumed by kudzu, are also subjected to eutrophication that reduces oxygen content, degrades the overall water quality, and harms the local organisms [15]. Eutrophication decreases the abundance of rare and native plant species while the species causing eutrophication, kudzu, intensifies in proliferation [15]. The longer kudzu remains in control of an area the less biodiversity exists. Water quality and biodiversity in the stream are used as indicators of the health of the surrounding environment [16] [17]. The decline of water quality and biodiversity brought on by the overabundance of kudzu can have long-term implications for a pristine natural stream. A natural pristine stream, which has a great diversity of vegetation and nutritional options, is necessary for local communities to subsist and develop. Diversity is crucial, and during certain times of the year, leaf diversity can affect the rate of leaf breakdown in a stream [18]. This could determine if nutritional resources are available for certain macroinvertebrates for feeding.

Ephemeroptera, Plecoptera, and Trichoptera are commonly referred to as EPT taxa. These taxa are commonly used as bioindicators to determine stream health. EPT taxa are sensitive environmental pollutants. Therefore, these taxa only thrive in healthy streams [19] [20]. Both Ephemeroptera and Plecoptera have aquatic stages that last for 1 - 4 years depending upon species [21]. Trichoptera feeding and growing seasons are usually in the winter and spring [21] [22]. Therefore, leaf degradation rates would greatly impact the life cycles of these organisms.

Research to determine whether leaf breakdown is an adequate tool for assessing stream health has been inconsistent [6] [23] [24]. More research is necessary to directly link the rate of leaf breakdown and macroinvertebrate abundance to 
the overall health of the stream and the possible ramifications of invasive plant species in the stream. The objective of this study was to establish leaf degradation rates of native and exotic vegetation in order to establish a connection a stream health. Three native trees in the genus Quercus (oak), genus Acer (maple), genus Liriodendron (tulip poplar) were compared to the exotic species Pueraria lobata (kudzu).

\section{Materials \& Methods}

A tributary of the Upper Yellow River in Lawrenceville, Georgia was chosen as the research area. The stream had a diverse and abundant canopy and adjacent to the stream were fields overgrown by Pueraria lobata, commonly known as kudzu. Three native leaf types were collected from around the sites based on the most common natural flora in the area. Approximately $150 \mathrm{~g}$ of genus Quercus (oak), genus Acer (maple), genus Liriodendron (tulip poplar), and 150g of kud$\mathrm{zu}$ leaves were collected.

The leaves were collected directly from plant species and dried approximately $31 \mathrm{C}$ for 48 hours to resemble naturally fallen leaves in the stream. Seven grams of each leaf type was weighed out with an electronic scale. Two waterproof labels identifying leaf type, the date to be removed, and stream location were placed in each bag. The leaf packs were secured with multiple overhand knots. There was a total of nine leaf packs of each of the leaf type. Then leaf packs were secured to paving bricks using 61 centimeters of twine and fishing line. Three fishing bobbers were also secured to the paving brick for identification purposes.

Sites in the stream with a minimum average depth of 31 centimeters were chosen and marked with red ribbon. Eight bricks were placed at each site. The bricks at each site were spread out to prevent entanglement while remaining clustered in the designated site. Every site had three leaf packs of each leaf type. Bags for every leaf type were located at each site. In addition, sets of leaf packs were designated for removal after 12, 24, and 36 days.

The water conditions and chemistry of each site were tested when the leaves were placed in the stream, and weekly from that date. The stream depth was recorded at three different places in each site. The depth was measured from the stream floor to the water surface using a meter stick. Water flow through each site was calculated three times a week, and the average water flow of each site was determined. Meter sticks were set up 153 centimeters apart, and a floatation device was released from the first stick. The time it took for the float to travel the 153 centimeters was tracked with a basic sports stopwatch, recorded, and used to calculate the water flow. The temperature, dissolved oxygen, and $\mathrm{pH}$ of each site were measured using an electronic water chemistry analysis device. The wand of the device was submerged in the water allowing the device to determine the temperature of the water, the percentage dissolved oxygen, the concentration of dissolved oxygen, and the $\mathrm{pH}$ of the water.

Packs designated for removal were collected with a kick net and placed into a 
sealed bag and transported to the lab. In the lab, the leaves were rinsed thoroughly through a fine-mesh sieve to separate the leaf-litter from other stream debris. The leaf-litter was dried for 12 hours at $50^{\circ} \mathrm{C}$ in an oven, and the weight was recorded. The samples were then ashed at $550^{\circ} \mathrm{C}$ for 45 minutes, and the material remaining was weighed to determine the ash-free dry mass.

The ash-free dry mass is used to determine the percentage of mass lost. The percent of mass lost was plotted against the time in the water. Using a standard exponential breakdown model, the slope of the regression of the natural log of the percent of mass remaining versus the time was used to determine the rate of leaf degradation. The variation in the rates of degradation for the leaves was compared with a 1-way ANOVA using SPSS Statistics 17.0. This was followed by Tukey, Scheffe, and Bonferroni post hoc multiple comparison tests to determine which of the leaves degraded at significantly different rates.

\section{Results}

\subsection{Leaf Degradation}

Leaf mass lost ranged from 19\% (oak) to 57\% (kudzu), while poplar and maple revealed a $45 \%$ and $34 \%$ mass lost. Poplar and kudzu had similar mass lost over the first 12-day period, but over the remaining 24-day period kudzu displayed a greater mass loss than polar. Average rates of degradation ranged from 0.0050 (oak) to 0.0201 (kudzu) with maple and poplar having degradation vales of 0.0102 and 0.0163 (Table 1). Species' with a low average degradation rates also exhibited a low leaf mass lost, which indicate a prolonged nutrient release into the ecosystem to support invertebrate survival.

Over the entire study period, oak leaves lost the least of their mass, only $19 \%$. Kudzu leaves lost $57 \%$ of their mass, the most of any leaf. Maple leaves had $66 \%$ of their mass remaining, while poplar leaves had only $55 \%$ of their mass remaining. During this period oak had the slowest rate of degradation at an average of 0.0050/day. Maple and poplar broke down at a faster rate of 0.0102/ day and $0.0163 /$ day, respectively. The fasted rate of breakdown was kudzu leaves at a rate of 0.0201/day. Oak had a slow rate of degradation. Maple had a medium rate of degradation, followed closely by poplar, which had a medium/fast rate of degradation. Kudzu had a fast rate of degradation (Figure 1 and Figure 2).

Table 1. The average percent of each leaf type remaining and rate of degradation after 36 days in the stream.

\begin{tabular}{cccccc}
\hline $\begin{array}{c}\text { Leaf } \\
\text { Type }\end{array}$ & $\begin{array}{c}\text { Average } \% \\
\text { Remaining }\end{array}$ & $\begin{array}{c}\text { Average Rate of } \\
\text { Degradation }\left(\text { day }^{-1}\right)\end{array}$ & Tukey (ANOVA) & P Value & Rate of Breakdown \\
\hline Oak & 81 & 0.0050 & Slower than Kudzu & 0.003 & Slow \\
Maple & 66 & 0.0102 & $\begin{array}{c}\text { Slower than Kudzu } \\
\text { Faster than other } \\
\text { native species }\end{array}$ & 0.015 & Medium \\
Poplar & 55 & 0.0163 & & Medium/Fast \\
Kudzu & 43 & 0.0201 & & Fast \\
\hline
\end{tabular}




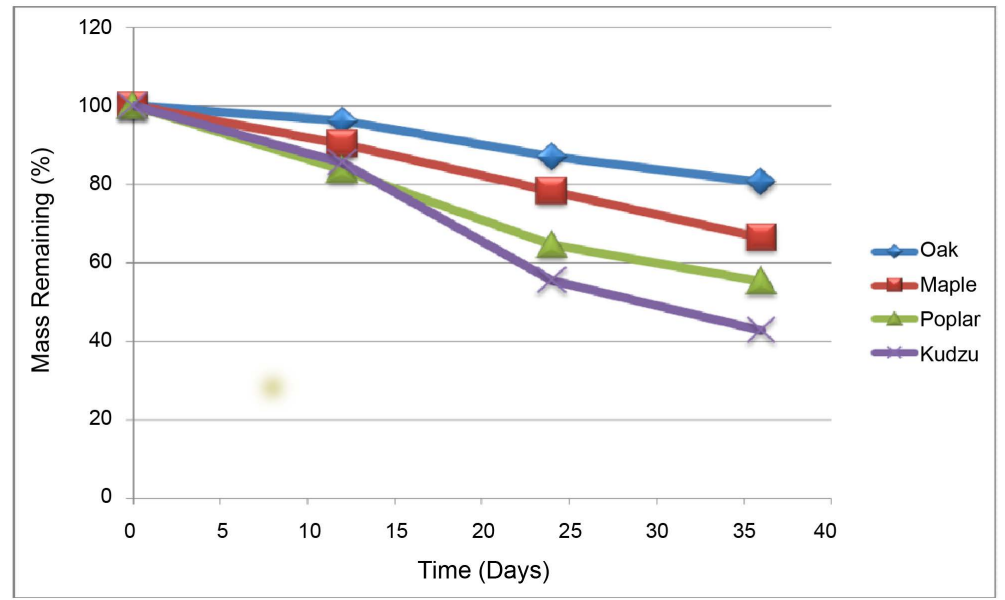

Figure 1. The mass remaining was plotted versus the amount of time the leaves were in the stream.

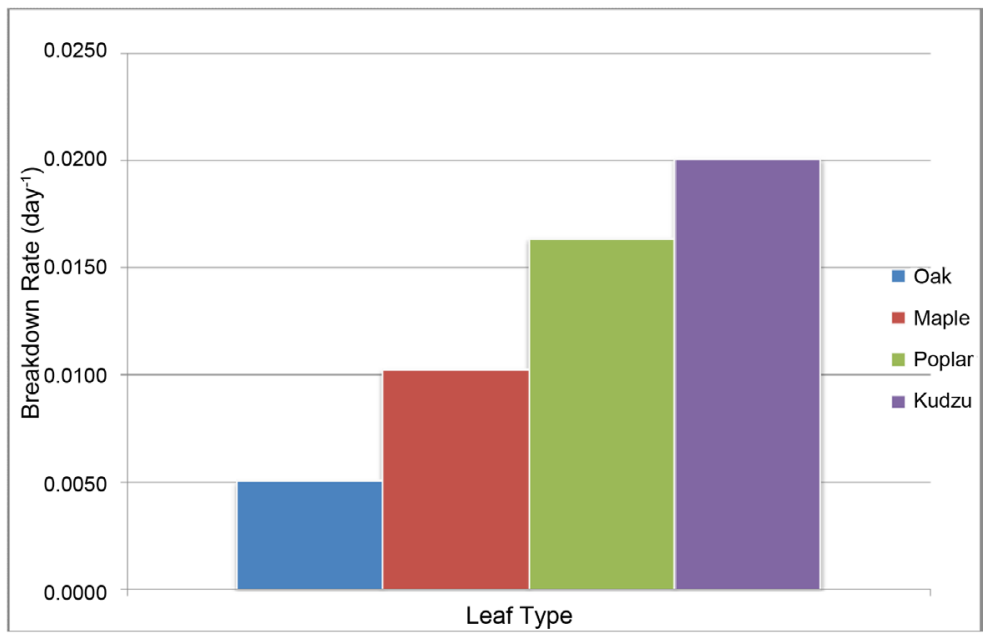

Figure 2. The average rate of breakdown over a 36 day period for each leaf type.

\subsection{Water Chemistry}

To understand the basic underlying parameters of the aquatic ecosystem, water chemistry was averaged for the three sites and graphed to compare the summer and fall. Water temperature showed an increase from in summer (Figure 3). During the fall, the temperature reached a low of $9{ }^{\circ} \mathrm{C}$, and during the summer the temperature reached a high of $27^{\circ} \mathrm{C}$. Dissolved oxygen was higher when the water temperature was cold, in the fall, and decreased as the water warmed (Figure 4). As the dissolved oxygen fluctuated, the $\mathrm{pH}$ responded accordingly. The $\mathrm{pH}$ was slightly higher in during the summer and lower in the fall (Figure 5). Also, the physical characteristics of the stream such as water flow and depth were collected. There was significant flooding event during the fall period of the experiment. As a result, after the flood, there was a significant spike in the water flow (Figure 6). Concurrently, water depth also showed an increase after the flood during the fall portion of the experiment (Figure 7). Finally, the rainfall illustrates the point at which the flooding occurred (Figure 8). 


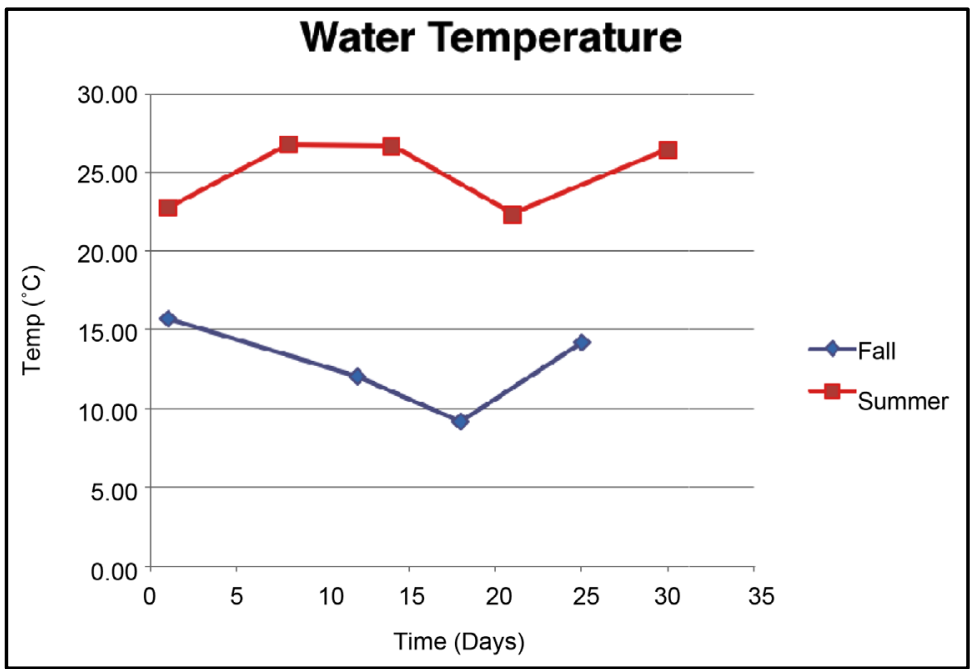

Figure 3. Water temperature in $\left({ }^{\circ} \mathrm{C}\right)$ for fall and summer.

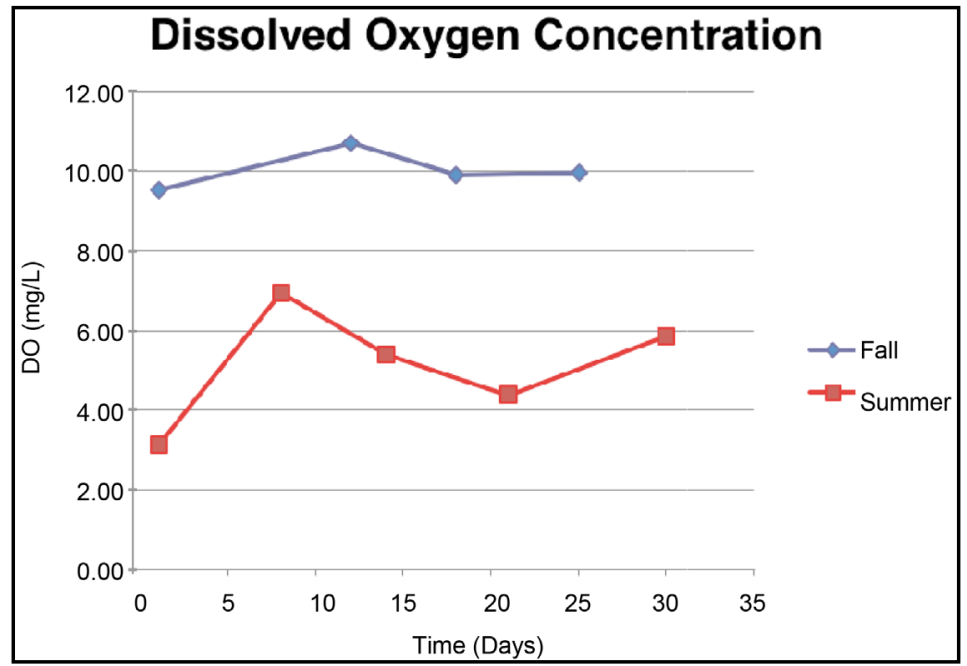

Figure 4. Dissolved oxygen, measured in $\mathrm{mg} / \mathrm{L}$ for summer and fall.

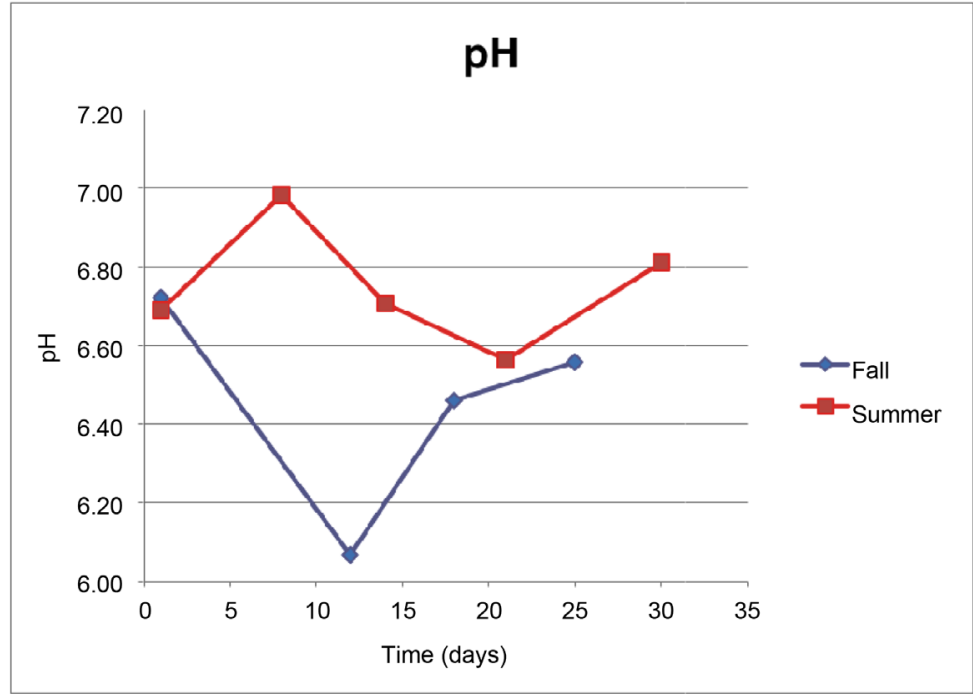

Figure 5. $\mathrm{pH}$ of the stream measured for the summer and fall. 


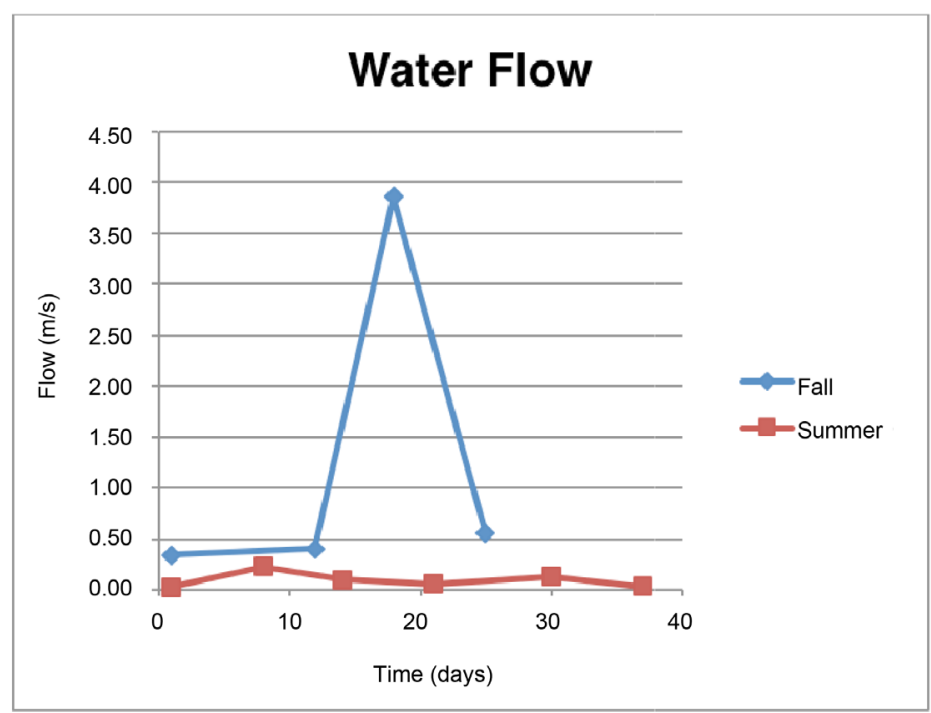

Figure 6. Flow of the stream measured in $\mathrm{m} / \mathrm{s}$ for the summer and fall.

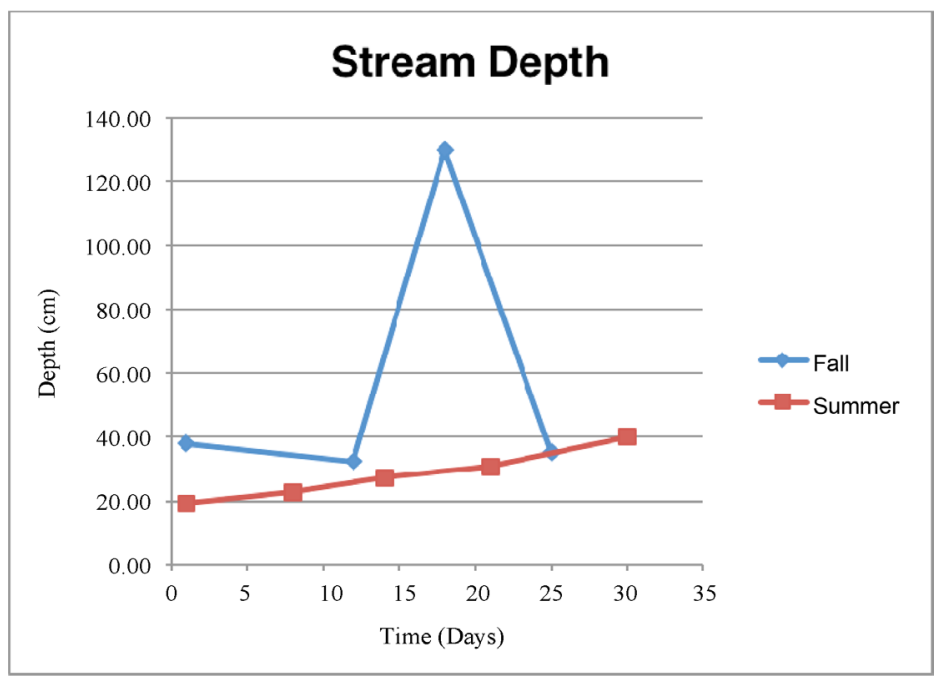

Figure 7. Stream depth measured in $\mathrm{cm}$ for the summer and fall.

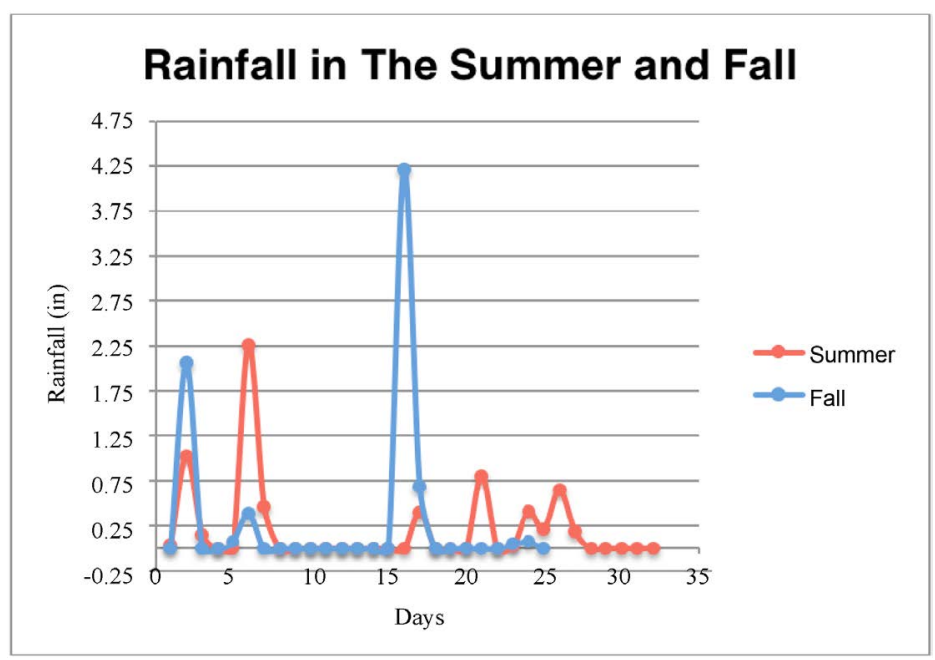

Figure 8. Rainfall measured in inches for the summer and fall. 


\section{Discussion}

Leaf type affects the rate of nutrient release into the stream [18]. The rate of leaf degradation is linked to the availability of particulate organic matter provided to the benthic zone for macroinvertebrates. Moreover, macroinvertebrates provide the flow of energy to higher organisms in the community [25]. Native leaves from the local canopy provided nutrients at a slow rate to a medium/fast rate. The exotic species in this study, like kudzu, released organic matter into the system at a fast rate. Therefore, if kudzu becomes the sole vegetative resource, the stream may only experience an influx of nutrient input for a short period.

Significant variation between leaf degradation rates was indicated in this study thus providing compelling evidence on invertebrate community structure. The most prominent variation was between that of kudzu and the two classes of native leaves. Kudzu degraded at a significantly faster rate than either oak or maple. After thirty-six days kudzu leaves had only $43 \%$ of their mass remaining. Oak leaves had over $80 \%$ of their mass remaining, and maple leaves still had over $65 \%$ of their original mass. There had been much more degradation of the kudzu leaves than oak or maple. Kudzu had released more nutrients into the stream in a shorter amount of time as compared to native leaves. Therefore, the entirety of the kudzu input would be broken down before the end of the season. The wide range of rates at which native leaves degrade, allow the leaves to release nutrients into the stream throughout the entire season. Oak leaves broke down at a slow rate, while maple leaves degraded at a medium rate and poplar broke down at a medium to fast rate. Poplar leaves provide a quick release of nutrients to the benthic zone, and with a slower breakdown rate, maple leaves provide nutrients further into the season. Finally, Oak, with the slowest rate of breakdown, could be a source of nutrients for benthic macroinvertebrates late in the season. This variation is key for the aquatic invertebrates, which rely on leaf debris for food and refuge, and this supply needs to extend into the spring and early summer when hatching occurs for some macroinvertebrates [21] [22].

Since several key invertebrates are often used to determine stream health, the overall impact between resources and community structure is a fundamental factor. Significant predictors of overall stream health are the presence of EPT taxa (Ephemeroptera, Plecoptera, and Trichoptera) [14] [19] [20] [26] [27]. These taxa are extremely sensitive to environmental disturbances as well as pollution, therefore, are prime indicator species. As that the aquatic stages of Ephemeroptera and Plecoptera extend from one to four years [21] changes in leaf degradation rates could greatly impact their life cycles. Knowing kudzu has a faster degradation rate, any ecosystem overridden with this species could only provide a nutrient influx for a limited time frame, thus, significantly impacting the invertebrate populations and stream health.

Unfortunately, when kudzu is introduced to an area it swiftly occupies the entire community [12]. As a result, kudzu rapidly becomes the primary nutritional source available to aquatic invertebrates. Furthermore, the faster degradation rates of kudzu would strongly affect resource availability. With a lone food source 
that has such a fast rate of degradation, the organisms would lack the necessary nutrients for their lifecycle. The biodiversity of the native leaves provides the system with the nutrients needed for local organisms to survive and regulate their life cycles by basing their lifecycles on when the most nutrients they need are available. Therefore, biodiversity of stream canopy will have a direct impact on the rate at which nutrients are released into a stream community [18].

The linkage between leaf species and leaf breakdown plays an integral part in the functioning of the stream's ecosystem. As the plant community is altered, the rate of leaf breakdown will also be altered resulting in changes in the leaf litter. This then drastically impacts the structure of the aquatic invertebrate community. Given this broad range of changes, this study further implies long term affects species diversity and species abundance in both invertebrate and plant communities. Thus, allowing the door to open for less sensitive taxa and impacting overall stream health as well as other functional ecosystem attributes.

\section{References}

[1] Paul, M., Meyer, J. and Couch, C. (2006) Leaf Breakdown in Streams Differing in Catchment Land. Fresh Water Biology, 51, 684-695.

https://doi.org/10.1111/j.1365-2427.2006.01612.x

[2] Woodward, G., et al. (2012) Continental-Scale Effects of Nutrient Pollution on Stream Ecosystem Functioning. Science, 336, 1438-1440. https://doi.org/10.1126/science.1219534

[3] Petersen, R.C. and Cummins, K.W. (1974) Leaf Processing in a Woodland Stream. Fresh Water Biology, 4, 343-368. https://doi.org/10.1111/j.1365-2427.1974.tb00103.x

[4] Sparks, T., et al. (2008) Leaf Degradation, Macroinvertebrate Shredders and Energy Flow in Stream. The American Biology Teacher, 70, 90-94. https://doi.org/10.1662/0002-7685(2008)70[90:LDMSEF]2.0.CO;2

[5] Gessner, M., et al., (2010) Diversity Meets Decomposition. Tends in Ecology and Evolution, 25, 372-380. https://doi.org/10.1016/j.tree.2010.01.010

[6] Hagen, E.M., Webster, J. and Benfield, E.F. (2006) Are Leaf Breakdown Rates a Useful Measure of Stream Integrity along with an Agricultural Land Use Gradient. Journals of the North American Benthological Society, 25, 330-334. https://doi.org/10.1899/0887-3593(2006)25[330:ALBRAU]2.0.CO;2

[7] Moore, J., et al. (2004) Detritus, Trophic Dynamics, and Biodiversity. Ecology Letters, 7, 584-600. https://doi.org/10.1111/j.1461-0248.2004.00606.x

[8] Wallace, J.B., et al. (1997) Multiple Trophic Levels of a Forest Stream Linked to Terrestrial Litter Inputs. Science, 277, 102-104. https://doi.org/10.1126/science.277.5322.102

[9] Feio, M.J., et al. (2010) Functional Indicators of Stream Health: A River Basin Approach. Freshwater Biology, 55, 1050-1065. https://doi.org/10.1111/j.1365-2427.2009.02332.x

[10] Robinson, C.T. and Jolidon, C. (2005) Leaf Breakdown and the Ecosystem Functioning of Alpine Streams. Journal of the North American Benthological Society, 24, 495-507. https://doi.org/10.1899/04-100.1

[11] Forseth, I. and Innis, A. (2004) Kudzu (Pueraria Montana) History Physiology and Ecology. Critical Reviews in Plant Sciences, 23, 401-413. 
https://doi.org/10.1080/07352680490505150

[12] Simberloff, D. (2008) Invasion Biologist and the Biofuels Boom: Cassandras or Colleagues. Weed Science, 56, 867-872. https://doi.org/10.1614/WS-08-046.1

[13] Terrill, T.H. (2003) Effect of Cutting Date and Frequency on Yield and Quality of Kudzu in Southeastern United States. Grass and Forage Science, 25, 178-183. https://doi.org/10.1046/j.1365-2494.2003.00369.x

[14] Davies, J.N. and Boulton, A. (2009) Great House, Poor Food: Effects of Exotic Leaf Litter on Shredders. Journal of the North American Benthological Society, 28, 491503. https://doi.org/10.1899/07-073.1

[15] Khan, F.A. and Ansari, A.A. (2005) Eutrophication: An Ecological Vision. The Botanical Review, 71, 449-482. https://doi.org/10.1663/0006-8101(2005)071[0449:EAEV]2.0.CO;2

[16] Rapport, D.J., Costanza, R. and McMichael, A.J. (1998) Assessing Ecosystem Health. TREE, 13, 397-402.

[17] Tolkkinen, M., et al. (2013) Decomposer Communities in Human-Impacted Streams: Species Dominate Rather than Richness Affect Leaf Decomposition. Journal of Applied Ecology, 50, 1142-1151. https://doi.org/10.1111/1365-2664.12138

[18] Swan, C.M. and Palmer, M.A. (2004) Leaf Diversity Alters Letter Breakdown in a Piedmont Stream. Journal of the North American Benthological Society, 23, 15-28. https://doi.org/10.1899/0887-3593(2004)023<0015:LDALBI>2.0.CO;2

[19] Ferro, M. and Sites, R. (2007) The Ephemeroptera, Plecoptera, and Trichoptera of Missouri State Parks with Notes on Biomonitoring, Mesohabitat Associations, and Distribution. Journal of the Kansas Entomological Society, 80, 105-129. https://doi.org/10.2317/0022-8567(2007)80[105:TEPATO]2.0.CO;2

[20] Hilsenhoff, W. (1988) Rapid Field Assessment of Organic Pollution with a Family-Level Biotic Index. Journal of the North American Benthological Society, 7, 6568. https://doi.org/10.2307/1467832

[21] Dobrin, M. and Giberson, D. (2003) Life History and Production of Mayflies, Stoneflies, and Caddisflies (Ephemeroptera, Plecoptera, and Trichoptera) in a Spring-Fed Stream in Prince Edward Island, Canada: Evidence for Population Asynchrony in Spring Habitats. Canadian Journal of Zoology, 81, 1083-1095. https://doi.org/10.1139/z03-091

[22] Wiggins, G. (1996) Biological Considerations. Larvae of the North American Caddisfly Genera (Trichoptera). University of Toronto Press.

[23] Pascoal, C., Cassio, F. and Gomes, P. (2001) Leaf Breakdown Rates: A Measure of Water Quality. International Review of Hydrobiology, 86, 407-416. https://doi.org/10.1002/1522-2632(200107)86:4/5<407::AID-IROH407>3.0.CO;2-P

[24] Wolfe, B. and Klironomos, J.N. (2005) Breaking New Ground Soil Communities and Exotic Plant Invasion. BioScience, 55, 477-487. https://doi.org/10.1641/0006-3568(2005)055[0477:BNGSCA]2.0.CO;2

[25] Karr, J. (1999) Defining and Measuring River Health. Freshwater Biology, 41, 221 234. https://doi.org/10.1046/j.1365-2427.1999.00427.x

[26] Chessman, B., Williams, S. and Besley, C. (2007) Bioassessment of Streams with Microinvertebrates. Journal of the North American Benthological Society, 26, 546565. https://doi.org/10.1899/06-074.1

[27] Young, R., Matthaei, C. and Townsend, C. (2008) Organic Matter Breakdown and Ecosystem Metabolism: Functional Indicators for Assessing River Ecosystem Health. Journal of the North American Benthological Society, 27, 605-625.

https://doi.org/10.1899/07-121.1 
Submit or recommend next manuscript to SCIRP and we will provide best service for you:

Accepting pre-submission inquiries through Email, Facebook, LinkedIn, Twitter, etc. A wide selection of journals (inclusive of 9 subjects, more than 200 journals)

Providing 24-hour high-quality service

User-friendly online submission system

Fair and swift peer-review system

Efficient typesetting and proofreading procedure

Display of the result of downloads and visits, as well as the number of cited articles Maximum dissemination of your research work

Submit your manuscript at: http://papersubmission.scirp.org/

Or contact ajps@scirp.org 